\title{
Dynamics of Erythropoietic Markers in Response to Hypoxia in Rats
}

\author{
Ying Zhang ${ }^{1,3}$, Indrajeet Singh ${ }^{1,2}$ and Wojciech Krzyzanski ${ }^{1 *}$
}

${ }^{1}$ Department of Pharmaceutical Sciences, State University of New York at Buffalo, Buffalo, New York, USA

${ }^{2}$ Amgen Inc., Thousand Oaks, CA, USA

${ }^{3}$ Clinical Pharmacology \& Pharmacometrics, CSL Behring, King of Prussia, PA, USA

\begin{abstract}
Purpose: Erythropoietin (EPO) regulates production of red blood cells in response to hypoxia. Decreased arterial oxygen saturation results in an increased production of EPO in various tissues including kidney as a major stimulation site leading to an increase in EPO plasma levels. This study aims to investigate the relationship between hypoxia and resultant erythropoietic response in rats.
\end{abstract}

Methods: The in house hypoxia chamber was designed to regulate the fraction of inspired oxygen $\left(\mathrm{FiO}_{2}\right)$ $=10 \%$ supplied to Wistar male rats $(\mathrm{N}=4)$ for 6 hours by mixing room air with $\mathrm{N}_{2}$ to maintain air pressure at 1 atm. Plasma and kidney samples were collected at various times during and after exposure to hypoxia. Kidney EPO mRNA, HIF-2 $\alpha$, plasma EPO concentration, reticulocyte counts and hemoglobin were measured. The time course of above markers and fold changes from pre-hypoxia values were used to quantify responses to hypoxia under the normoxic condition.

Results: The arterial oxygen saturation of rats decreased from $95 \%$ to $60 \%$ during the hypoxia. Hypoxia resulted in 6-fold increase in kidney EPO mRNA expression, 10-fold increase in plasma EPO concentrations and 1.5-fold increase in reticulocytes count. The increase of HIF-2 $\alpha$ expression is 2.4 fold after one hour hypoxia and returns below the baseline value after 1.5 hours. The result of DNA binding activity of HIF-2 $\alpha$ is quite similar, which increased 1.5 fold at 0.5 hour and then went below baseline.

Conclusion: After 6 hours hypoxia, the observed increase in the levels of kidney EPO mRNA, plasma EPO concentrations and reticulocytes count, and delays in peak response are consistent with times necessary for the stimulation for EPO mRNA transcription, synthesis of plasma EPO, and enhanced release of reticulocytes. The tolerance effect observed in HIF-2 $\alpha$ time course implies existence of a counter-regulatory mechanism in a HIF-2 $\alpha$ mediated signal for mRNA production.

Keywords: Hypoxia; Erythropoiesis; Hypoxia-inducible factor

\section{Introduction}

Atmospheric $\mathrm{PO}_{2}$ reduction causes drop in arterial $\mathrm{PO}_{2}$ and the arterial oxygen saturation resulting in the state of hypoxia [1]. The kidney is a highly sensitive oxygen sensor and plays a central role in mediating the hypoxic induction of red blood cell production [2]. In response to hypoxia, the kidney secretes the hormone erythropoietin (EPO) that induces erythropoiesis through the stimulation of erythroid precursor cell viability, proliferation, and differentiation, thus enhancing the oxygen-carrying capacity of blood $[3,4]$. The kidneys are the major site of EPO production under hypoxic conditions, in minor amounts, but other organs such as the liver and the brain also produce EPO [5].

Efforts to understand the molecular basis of oxygen-regulated erythropoiesis have led to the identification hypoxia-inducible factor (HIF), the transcription factor that regulates EPO synthesis and mediates cellular adaptation to hypoxia. HIFs are heterodimeric transcriptional regulators consisting of distinct oxygen-sensitive $\alpha$-subunits (such as HIF- $1 \alpha$, HIF- $2 \alpha$, or HIF-3 $\alpha$ ) and a stable $\beta$-subunit [6]. Under normoxic conditions, HIF-1 is rapidly degraded by the proteasome. However, under hypoxic conditions, human HIF-1 is stabilized and permits the activation of genes essential for cellular adaptation to low oxygen conditions including EPO. HIF is primarily regulated by specific prolyl hydroxylase-domain enzymes (PHDs) which are sensitive to oxygen and initiate its degradation via the von Hippel-Lindau tumor suppressor protein (VHL) $[7,8]$. Under hypoxia, degradation is inhibited and HIF- $\alpha$ can be transferred to the nucleus where it recruits HIF- $\beta$ and the transcriptional coactivator $\mathrm{p} 300$ for its activation [6]. For binding of HIF- $\alpha$ to the EPO enhancer and full transactivation of the EPO gene, the interaction with another transcription factor that binds to cis-active elements in the vicinity of the hypoxia-response elements (HREs) is an absolute requirement [9].

In the normoxia, the key reactions are hydroxylation of the HIF-2 $\alpha$ by PHDs and the ubiquitination of hydroxylated HIF-2 $\alpha$ by VHL with the availability of oxygen and iron. But under the hypoxic conditions, the hydroxylation of HIF-2 $\alpha$ by PHDs is inhibited and proteasomal degradation is slowed. HIF- $2 \alpha$ rapidly accumulates and dimerises with HIF- $1 \beta$ to form a DNA binding complex that up-regulates hypoxiaresponsive genes, including EPO and vascular endothelial growth factor (VEGF) [10]. This DNA binding complex bind to specific DNA recognition sequences, HRE, to activate the transcription [10].

Although the prototype HIF-1a was discovered in studies of EPO, later investigations have identified HIF-2 $\alpha$ (also called EPAS1 for endothelial PAS domain protein 1) as the primary transcription factor

*Corresponding author: Wojciech Krzyzanski, Department of Pharmaceutical Sciences, State University of New York at Buffalo, Buffalo, New York, USA, E-mail:wk@buffalo.edu

Received December 13, 2013; Accepted January 27, 2014; Published February 04, 2014

Citation: Zhang Y, Singh I, Krzyzanski W (2014) Dynamics of Erythropoietic Markers in Response to Hypoxia in Rats. J Blood Disorders Transf 5: 197. doi: 10.4172/2155-9864.1000197

Copyright: ( 2014 Zhang Y, et al. This is an open-access article distributed under the terms of the Creative Commons Attribution License, which permits unrestricted use, distribution, and reproduction in any medium, provided the original author and source are credited. 
inducing EPO expression [4,9,11-13]. In their study, mRNA induction of EPO after exposure of Hep3B cells and neuroblastoma Kelly cells to hypoxia was almost abolished by the HIF-2a siRNA whereas HIF-1 $\alpha$ knockdown had no effect. EPO is a HIF- $2 \alpha$ target gene and transactivation of the EPO enhancer by HIF- $2 \alpha$ requires cis-active elements adjacent to the HRE, but the HIF-1 $\alpha$ target genes are VEGF, GLUT-1 and LDH-A [9]. Consequently, HIF- $2 \alpha$ instead of HIF-1 $1 \alpha$ may be considered as the primary hypoxia inducible factor to investigate the transcriptional activation of EPO gene and regulation of the EPO production after mild hypoxia treatment.

After the transactivation of EPO gene, the Northern blot analyses of RNA from murine kidneys show a great fold increase in the level of EPO mRNA in the presence of hypoxia [14]. Associate with the increase of EPO mRNA, the production of EPO increased, and this hormone stimulates proliferation and differentiation of erythroid progenitors, production of reticulocytes and red blood cells, which activates increased erythropoiesis in the hemopoietic tissues, ultimately increasing hemoglobin levels [5].

In this study, we investigated the relationship between hypoxia and resultant erythropoietic responses in rats. We determined the time courses of the erythropoietic markers such as HIF-2 $\alpha$, EPO mRNA in kidney, and EPO, reticulocytes, and hemoglobin in blood during and after intermittent normobaric hypoxia. Our objective was to quantify the impact of these factors on each other in a longitudinal way in response to hypoxia.

\section{Methods}

\section{Animals}

All studies were approved by the Institutional Animal Care and Use Committee of the University at Buffalo. Male Wistar rats with weights ranging from 300 to $350 \mathrm{~g}$ were purchased from Charles River Laboratories, Inc. (Raleigh, NC). All animals had free access to fresh water and food pellets and were kept under standard conditions with 12 hours light/dark cycles. Animals were acclimatized for one week before the initiation of the studies.

\section{Hypoxia}

To create hypoxic conditions, a $70 \times 30 \times 30 \mathrm{~cm}$ plexiglass chamber was custom built to fit at least two rat cages inside (Figure 1). Food and water was made available in their cages for the whole duration of study conducted. The gas mixture $\left(10 \% \mathrm{O}_{2}-90 \% \mathrm{~N}_{2}\right)$ for up to 6 hours was delivered at $\sim 2.5 \mathrm{l} / \mathrm{min}$ at the atmospheric pressure by mixing room air with the medical grade $\mathrm{N}_{2}$. $\mathrm{N}_{2}$ flow was controlled by a gas flowmeter (GFM 17 low flow mass flow meter, Aalbrog, Orangeburg, NY). The $\mathrm{O}_{2}$ level and temperature in the chamber were constantly monitored using OXOR II Oxygen Analyzer (Bacharach, New Kensington, PA) for the duration of hypoxia. For post hypoxic studies, chamber was opened immediately after stopping hypoxia and rats remained inside the chamber up to the desired post hypoxic exposure period. Our study design required exposing rats to $10 \%$ hypoxia for $0.25,0.5,1,1.5,2,3,4$ and 6 hours. For the post hypoxic period, after exposing rats to 6 hours of hypoxia at $10 \%$, rats were allowed to breathe normal air for 1,3 and 6 hours. At least four rats were exposed to each hypoxic measurement. For reticulocytes and hemoglobin measurements, only two rats were used for a single hypoxic exposure of $10 \%$ for 6 hours. Thereafter animals were transferred to their cages.

\section{Arterial oxygen saturation}

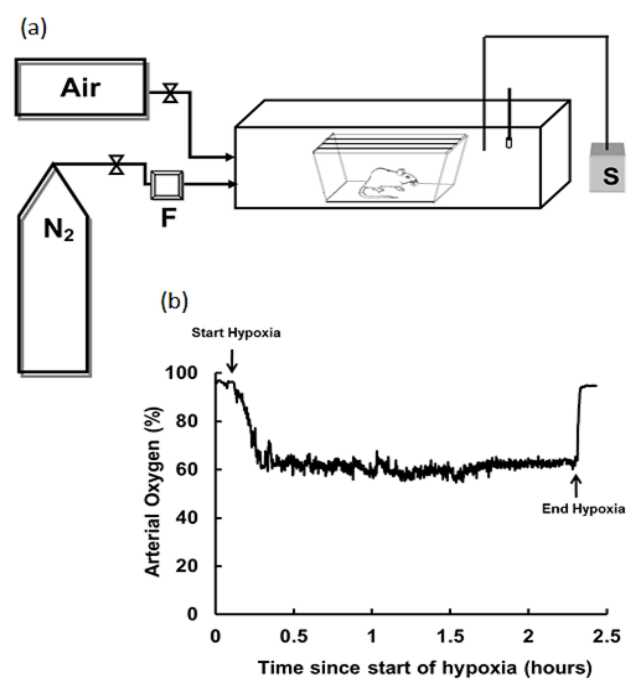

Figure 1: (a) Schematic of hypoxia chamber. F (Flow Controller), S (Oxygen Sensor), $T$ (Thermometer). In lower panel is a typical hypoxia implementation scheme. (b) A representative plot of measured arterial oxygen saturation (\%) after single $10 \%$ hypoxic exposure of 2 hours to rats. Two solid arrows indicate the start and end of hypoxia.

We measured blood oxygen saturation in a subset of rats $(\mathrm{N}=3)$ for hypoxic treatment of $10 \%$ for 1 hour and 2 hours using Mouse Ox pulse oximeter (Starr Life Sciences Corp., Oakmont, PA) mounted on their neck using collar clip sensor. The data collection was done at measurement response frequency of $1 \mathrm{~Hz}$ and breath rate along with heart rate was constantly monitored for each rat. Rats were anesthetized by urethane (Sigma-Aldrich, Saint Louis, MO) treatment at $2 \mathrm{~g} / \mathrm{kg}$. The measurements are reported as percentage arterial oxygen saturation.

\section{Tissues and blood samples preparation}

Rats were sacrificed immediately at the end of the study by exsanguination following deep gas anesthesia. Kidney tissues were collected immediately and flash frozen in liquid nitrogen. It has been reported that HIF- $2 \alpha$ degradation due to reoxygenation depends on the time interval end of hypoxia and freezing the tissue [15]. Therefore all the operations have been done within 10 minutes to minimize the oxygen contact in rats. Blood was collected in 10\% EDTA. Whole blood was used for reticulocyte and $\mathrm{CBC}$ analysis immediately after collection. Plasma was used for EPO concentration measurements. Tissue and plasma samples were stored at $-80^{\circ} \mathrm{C}$.

\section{ELISA analysis for HIF-2 $\alpha$ of DNA binding activity}

HIF-2 $\alpha$ DNA binding activity of the nuclear fraction was determined by using a commercial ELISA-based kit (Active Motif, Carlsbad, CA, USA) according to the manufacturer's specifications. DNA-binding activity was expressed as optical density at $450-655 \mathrm{~nm}$ relative to that of control and represented triplicate samples from two independent experiments. The only difference compared with the commercial kit was the change of the primary antibody from the kit for HIF-1a to another primary antibody for HIF-2 $\alpha$ (mouse monoclonal anti-HIF$2 a$, Novus Biologicals). We used HeLa $\left(\mathrm{CoCl}_{2}\right)$ nuclear extract which was provided in the kit as a positive control for both HIF-1 and HIF-2 activation. The result showed that there is no difference in the binding activity between the two transcription factors. The reason is that all the transcription factors containing basic helix-loop-helix (bHLH) and PER-ARNT-SIM homology domains, such as the HIF-1 $\alpha$ and HIF-2 $\alpha$, 
have similar structure [16]. Their HIF heterodimers bind to the same hypoxia response element (HRE), a 5'-RCGTG-3' consensus sequence $[4,17]$. Therefore, the DNA binding activity of these two transcription factors can be detected using same pre-coated well from the same kit. The specificity of the antibody was confirmed by the positive control in the kit and verified by Western blot analysis shown in Figure 2 .

\section{Western blot analysis}

Nuclear protein extraction was performed on the kidney cortex samples using the commercial nuclear extract kit (Active motif, Carlsbad, CA, USA) according to the manufacture's protocol. Total protein concentration was determined with Protein Assay Dye Reagent Concentrate (Bio-Rad, Hercules, CA, USA). $50 \mu \mathrm{g}$ nuclear protein extract was loaded into a 10\% SDS-PAGE gel and separated after 2 hours of electrophoresis at $80 \mathrm{~V}$. After the transfer, the membranes were blocked in $5 \%$ non-fat milk overnight and blotted with mouse monoclonal anti-HIF-2 $\alpha$ (Novus Biologicals, Littleton, CO, USA) 1:400 and mouse monoclonal beta-actin (Novus Biologicals, Littleton, CO, USA) 1:1000 for 2 hours at room temperature. The secondary antibody was rabbit anti-mouse IgG conjugated with HRP (Novus Biologicals) diluted at 1:1000 and incubated for 1 hour. Membranes were developed with the Super Signal West Pico Chemiluminescent Substrate (Pierce, Rockford, IL, USA).

\section{RNA isolation and quantitative real-time PCR of EPO mRNA}

Total RNA isolation Total RNA was isolated from the rat kidney cortex using the SV Total RNA isolation system (Promega, Madison, WI, USA) and isolated RNA samples were treated with DNase I following the manufacturer's instructions. The RNA concentration was determined by absorbance at $260 \mathrm{~nm}$, and the $260 \mathrm{~nm}$ to $280 \mathrm{~nm}$ ratio of each sample was greater than 1.8 to ensure RNA integrity. After isolation total RNA was immediately used for next step, cDNA synthesis.

\section{cDNA preparation}

From every isolated total RNA sample $4 \mu \mathrm{g}$ was converted to cDNA by adding a reaction mixture containing $1 \mu$ l Strata Script reverse transcriptase (Strata gene, La Jolla, CA, USA), $5 \mu$ l Strata Script 10X first strand buffer, $1 \mu$ loligo-(dT) $(1 \mu \mathrm{g} / \mu \mathrm{l}), 10 \mu$ ldNTPs $(5 \mathrm{mM}$ each) [1117]. The total reaction volume was adjusted to $50 \mu \mathrm{l}$ by adding RNase free distilled water. The reaction mixtures were incubated at $42^{\circ} \mathrm{C}$ for 45 min and then at $95^{\circ} \mathrm{C}$ for $5 \mathrm{~min}$ to inactivate the reaction mixture. The cDNA samples were stored at $-20^{\circ} \mathrm{C}$. These $\mathrm{cDNA}$ samples were used to perform QPCR.

\section{Real time quantitative PCR}

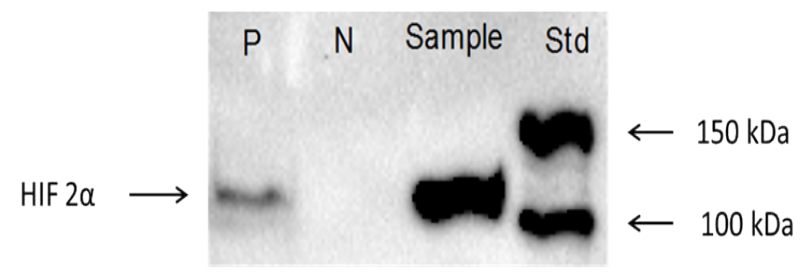

Figure 2: Western blot image for positive control $(P)$, negative control $(\mathrm{N})$, sample (nuclear extract from kidney of 1-hour hypoxia treated rat) and molecular weight ladder (L) demonstrates the HIF-2a (118 kDa) can be detected using the specific HIF-2 $\alpha$ antibody and there is no cross-reaction with other proteins, $(\mathrm{N}=4)$. *Values significantly different compared with the control group $\left({ }^{*} P<0.05\right.$, $\left.{ }^{* *} P<0.01,{ }^{* *} P<0.001\right)$.
QPCR were performed on EPO cDNA and housekeeping gene 18s rRNA using the Strata gene Mx4000TM Multiplex Quantitative PCR System (Strata gene, La Jolla, CA, USA). For these experiments the SABioscience primer set (PPR06628B-200 for rat Epo and PPR57734E-200 for rat $18 \mathrm{~S}$ rRNA) and $\mathrm{RT}^{2}$ SYBR $^{\circledR}$ Green qPCRMastermixes (PA-012) were used per manufacturer's instructions [18]. Each EPO sample was assayed in triplicate, following the polymerase activation at $95^{\circ} \mathrm{C}$ for $10 \mathrm{~min}$, followed by amplification consisting of 40 cycles of $15 \mathrm{sec}$ at $95^{\circ} \mathrm{C}$, followed by 1 minute at $60^{\circ} \mathrm{C}$.

To obtain the standard curve for EPO, we followed the protocol described by the manufacturer. Briefly, the PCR product for EPO was cloned into a PCR 2.1 TOPO vector (Invitrogen, Carlsbad, CA, USA) and transformed into One Shot chemically competent Escherichia coli cells (Invitrogen, Carlsbad, CA, USA). Plasmid containing the PCR product sequence was extracted from E. coli cells using a Wizard plus Minipreps DNA purification system (Promega, Madison, WI, USA). The product was resolved by electrophoresis through a $1.2 \%$ agarose gel to confirm target size and the presence of a single PCR product. The standard curves using dilution of DNA were run in duplicates along with the unknown samples. The reported copy number was estimated from the linear regression of the standard curve on the same plate. The final result was normalized by the housekeeping gene from each sample and presented as the fold change to compare mRNA expression levels under various levels of hypoxic treatment.

\section{Plasma EPO protein}

Plasma concentration of endogenous EPO was measured using Quantikine rat EPO ELISA kit (R\&D Systems, Minneapolis, MN, USA). This assay employs the quantitative sandwich enzyme immunoassay technique. A monoclonal antibody specific for rat EPO is pre-coated onto a microplate. All reagents and standard dilutions of control and samples were prepared per manufacturer's instructions. In brief, $50 \mu \mathrm{l}$ assay diluent was added to each well in the plate, then $50 \mu \mathrm{l}$ of standard, control or sample was added to the plate and incubated at room temperature for 2 hours on shaker. Each well was aspirated and rinsed with wash buffer for a total of five washes. $100 \mu \mathrm{l}$ of EPO conjugate was added to each well and plate was incubated for 2 hours at room temperature on a shaker. Aspiration and washing were repeated again. $100 \mu \mathrm{l}$ of substrate was added in each well and incubated for $30 \mathrm{~min}$ in dark. $100 \mu$ of stop solution was added and samples were read within 30 minutes. Plate was read at $450 \mathrm{~nm}$ on a SpectraMax 190 ELISA plate reader (Molecular Devices, Sunnyvale, CA). Based on the standard curve, absorption values were converted to $\mathrm{pg} / \mathrm{ml}$ for each well. Each sample was measured in duplicates.

\section{Reticulocytes and hemoglobin}

Reticulocyte counts were obtained using flow cytometry (FACSCalibur; BD Biosciences, Franklin Lakes, NJ) with the thiazole orange stain (Retic-reagent; BD Biosciences). All procedures were based on the manufacturer's instructions. In brief, $5 \mu$ l of EDTAtreated whole blood was added to tubes containing $1 \mathrm{ml}$ of staining solution with thiazole orange and incubated for 1 hour in the dark at room temperature. In addition, a control sample was prepared by adding $5 \mu \mathrm{l}$ of the whole blood to $1 \mathrm{ml}$ of phosphate-buffered-saline. Green fluorescence from thiazole orange bound to RNA residuals in reticulocyte was determined as a percentage of positive events (\%RET) in the region of RBCs by setting a threshold using an unstained control. For each blood sample complete blood counts were obtained from the Mindray BC-2800 Auto Hematology Veterinary Blood Analyzer (Mahwah, NJ). The absolute reticulocyte counts were then calculated 
by multiplying \%RET by the RBC counts.

\section{Statistical analysis}

Results are presented as mean \pm standard deviation. A parametric one-way ANOVA using R was used to test for any differences among the groups. If the result was found significant, the Dunnett multiple comparison test was then used to determine the specific differences between group means $\mathrm{P}<0.05$ was considered to be statistically significant [19]. $\mathrm{N}=4$ animals were used for all measurements except for reticulocyte and hemoglobin evaluation where $\mathrm{N}=2$ due to loss of two animals during experiment.

\section{Results}

\section{Hypoxia}

As a result of hypoxic condition in the chamber, lower level of oxygen in the chamber induces drop in arterial oxygen in rats. At $10 \%$ applied hypoxia, $\left(A_{O 2}\right)$ ss (oxygen level at steady state) in rats dropped significantly to an average of $\sim 60 \%$ while compared with normal $\left(A_{\mathrm{O}_{2}}\right)_{0}$ of $\sim 94 \%$ in the absence of hypoxia. Figure $1 \mathrm{~b}$ shows a typical profile of $A_{\mathrm{O} 2}$ measured in rats for 2 hours of applied hypoxia. With the drop in oxygen level inside the chamber the $A_{\mathrm{O} 2}$ value in rats also starts to decline with time. The percentage of oxygen level in the chamber drops from $\sim 20.9 \%$ to $10 \%$ within 10 minutes of applied hypoxia, whereas $A_{O 2}$ in rats reaches a steady state value of $\sim 60 \%$ within 20 minutes of applied hypoxia. The $A_{\mathrm{O} 2}$ plateau value remains stable for the duration of applied hypoxia and returns to its baseline $\left(A_{\mathrm{O} 2}\right)_{0}$ immediately after stopping the hypoxia. Hypoxia-inducible factor HIF- $\alpha$ subunit is continuously synthesized but rapidly destroyed in the presence of oxygen and iron. Under the applied hypoxic conditions (10\% hypoxia), HIF- $\alpha$ rapidly accumulates and dimerises with HIF- $\beta$, that is expressed constitutively and is present in excess [10].

\section{HIF- $2 \alpha$}

HIF- $2 \alpha$ is the primary hypoxia inducible factor of EPO gene; therefore we measured HIF- $2 \alpha$ as the first marker of response to hypoxia. We studied the protein expression and DNA binding activity of HIF- $2 \alpha$ by using Western blot and ELISA. As shown in Figure 3a, we observed an initial decline in HIF-2 $\alpha$ a protein expression level that was followed by a significant 2.5 fold increase after $1 \mathrm{hr}$ of applied hypoxia. Although, the hypoxic exposure was maintained at $10 \%$ for $6 \mathrm{hrs}$, the peak of HIF-2 $\alpha$ expression was short lived, and HIF- $2 \alpha$ drops below its baseline levels within 2 hrs on hypoxia. We did not observe HIF-2a returning to baseline levels up to six hours of posthypoxicnormoxia treatment, though the difference was not statistically significant. DNA binding activity of HIF-2a is shown in Figure $3 b$. The trend of this curve is quite similar to the one of protein expression. The binding increased by $\sim 50 \%$ within first $30 \mathrm{~min}$ of applied hypoxia, that followed by drop in activity during the course of applied hypoxia. The maximum drop in activity was about 2 fold that was observed at the end of hypoxia. This also suggests that the DNA binding activity is faster than the protein expression after the hypoxia treatment.

\section{EPO mRNA}

In order to know the change of transcriptional activation of the HIF-2 $\alpha$ DNA binding complex over the time following hypoxia, the EPO mRNA levels were measured by real-time PCR analysis and the results are shown in Figure 4. 10\% Hypoxia results in a continuous increase EPO mRNA in rat kidney cortex. The peak of the 6-fold change is followed by a gradual return to the baseline value immediately after

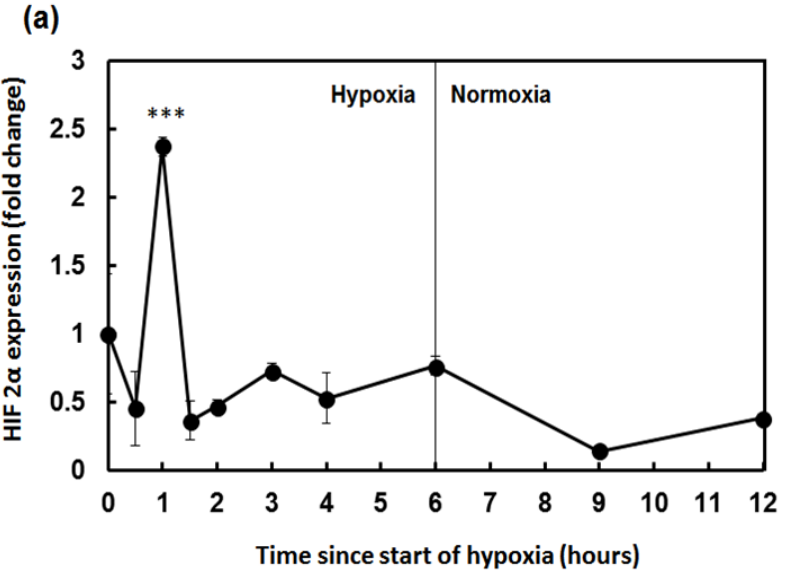

(b)

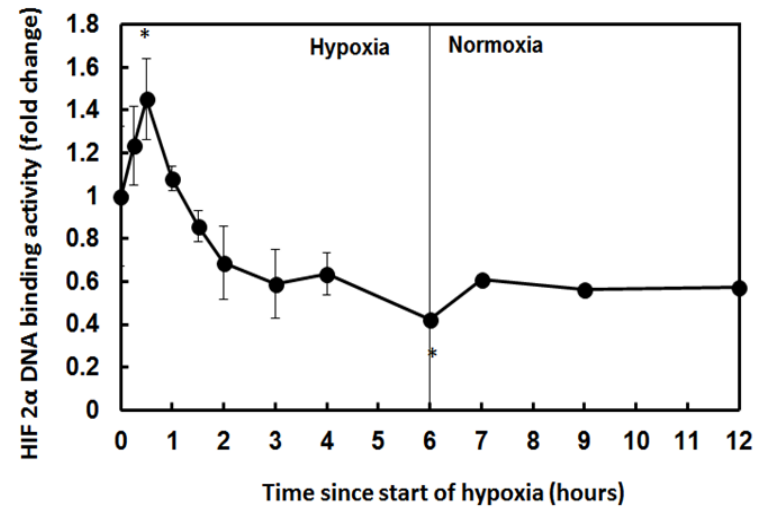

Figure 3: (a) Mean $\pm \mathrm{SD}(\mathrm{N}=4)$ of HIF-2 $\alpha$ protein expression in the kidney cortex of rats in response to $10 \%$ hypoxia for 6 hours. (b) Mean $\pm S D(N=4)$ of HIF-2 $\alpha$ DNA binding activity in the kidney cortex of rats exposed to the same hypoxia conditions. *Values significantly different compared with the control group $\left({ }^{*} P<0.05,{ }^{* *} P<0.01,{ }^{* *} P<0.001\right)$.

stopping the hypoxia over the post hypoxia period up to 12 hours.

\section{Plasma EPO}

An increase in EPO mRNA can stimulate the production of EPO in plasma during the translation. The plasma EPO concentrations are shown in Figure 5. The plasma EPO concentrations remained at the baseline of $200-500 \mathrm{pg} / \mathrm{ml}$ for first four hours. After 4 hours, the level of plasma EPO concentration rapidly increased until the 6 hours when the hypoxia stopped. The value of peak was $3000 \mathrm{pg} / \mathrm{ml}$, which translated to about 10 fold increased in plasma EPO compared with the normoxia levels. When the hypoxia terminated, similar to the EPO mRNA, the plasma EPO slowly declined to its baseline value, which was reached before 12 hours.

\section{Reticulocytes}

Plasma EPO stimulates the production of progenitor red blood cells including reticulocytes [5]. We measured blood reticulocyte counts as shown in Figure 6a. We followed two rats for reticulocyte counts after 6 hours of single 10\% hypoxic exposure. Reticulocytes were measured up to 9 days during post hypoxia period. Prior to hypoxia 


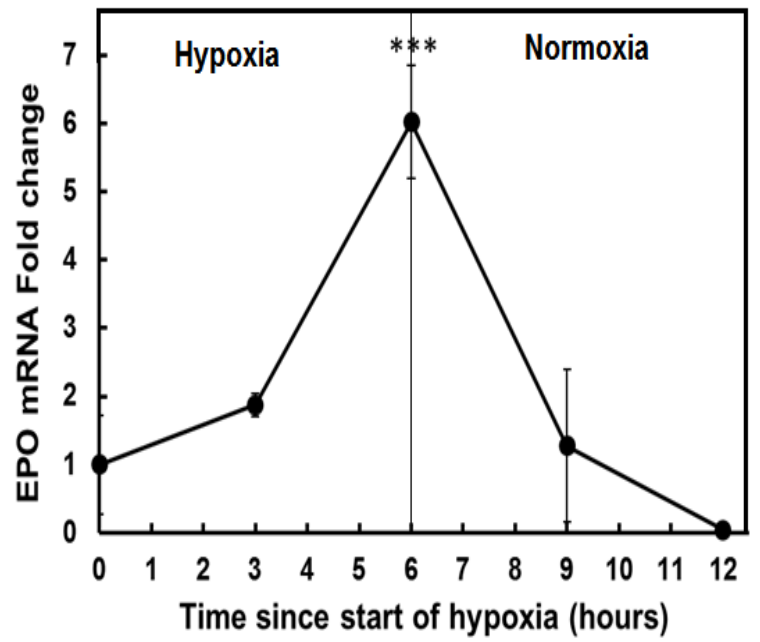

Figure 4: 10\% hypoxia administered for $0,3,4,6,7,9,12$ hours results in stimulation of erythropoietin (EPO) mRNA in rat kidney cortex. mRNA levels were quantified by qRT-PCR result fold change normalized by 18s rRNA housekeeping gene, $(\mathrm{N}=4)$. *Values significantly different compared with the control group $\left({ }^{\star} P<0.05,{ }^{* *} P<0.01,{ }^{* * *} P<0.001\right)$.

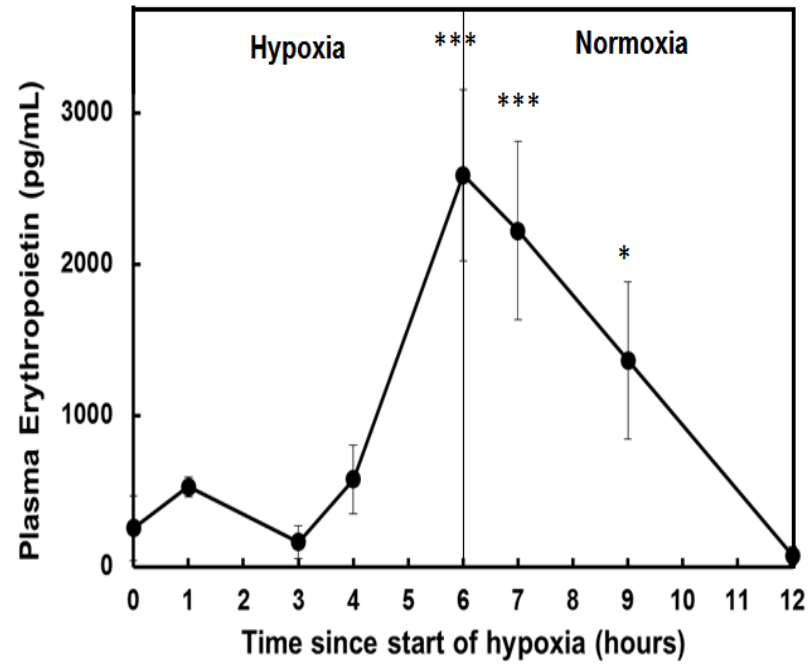

Figure 5: Mean $\pm \mathrm{SD}(\mathrm{N}=4)$ of plasma erythropoietin levels measured in response to $10 \%$ hypoxic exposure for 6 hours. *Values significantly different compared with the control group $\left({ }^{*} P<0.05,{ }^{* *} P<0.01,{ }^{* * *} P<0.001\right)$.

event, the baseline reticulocyte count was $21.6 \pm 2.6\left(10^{4} \mathrm{cells} / \mu \mathrm{l}\right)$. The reticulocytes count gradually increased to reach the peak of $31.9 \pm 6.5$ $\left(10^{4}\right.$ cells/ $\left.\mu \mathrm{l}\right)$ after 2 days that followed by decrease to a plateau of $15 \times$ $10^{4}$ cells/ $\mu$ l during days 6 to 9 .

\section{Hemoglobin}

Production of hemoglobin continues in the erythroid cell throughout its early development from the proerythroblast stage until the reticulocyte phase. The increase in the reticulocyte count is followed by an increased level of hemoglobin. The hemoglobin time course is shown in Figure $6 \mathrm{~b}$. We followed the rats for hemoglobin levels after 6 hours of single $10 \%$ hypoxic exposure, and hemoglobin levels were measured up to 9 days during post hypoxia period. The hemoglobin levels prior to hypoxia event are quite similar to the levels after hypoxia, which are in the normal range between $11 \mathrm{~g} / \mathrm{dl}$ and $12.5 \mathrm{~g} / \mathrm{dl}$. The peak of hemoglobin measurements was significantly different from prehypoxia values $(P<0.05)$.

\section{Discussion}

Generally, our measurements confirm findings on the response of erythropoietic markers caused by hypoxia reported in the literature. The fold change of biomarkers on time scale after hypoxia treatment is shown in Figure 7. The behavior of EPO mRNA, reticulocytes and hemoglobin are consistent with the results from studies where rats were treated with EPO [20]. However, the protein expression and DNA binding activity of HIF- $2 \alpha$ exhibit an unexpected behavior. The fold change of HIF-2 $\alpha$ increased very fast, within 1 hour and rapidly declined despite exposure to hypoxia for another 5 hours. This phenomenon is known in pharmacodynamics as a tolerance effect [21] Table 1.

In previous studies, it has been confirmed that the HIF- $2 \alpha$, not the HIF- $1 \alpha$, is the main protein to regulate the production of EPO. Based on the results from Rankin et al., using chromatin immunoprecipitation

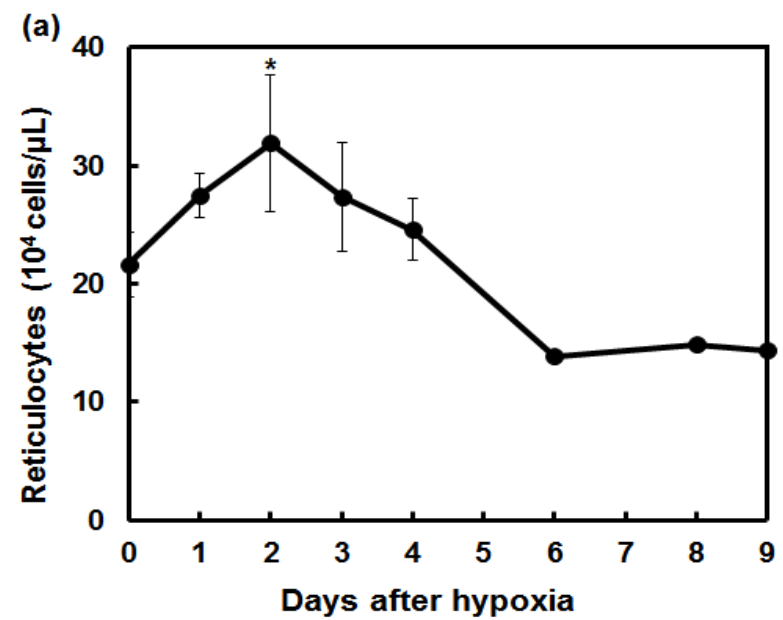

(b)

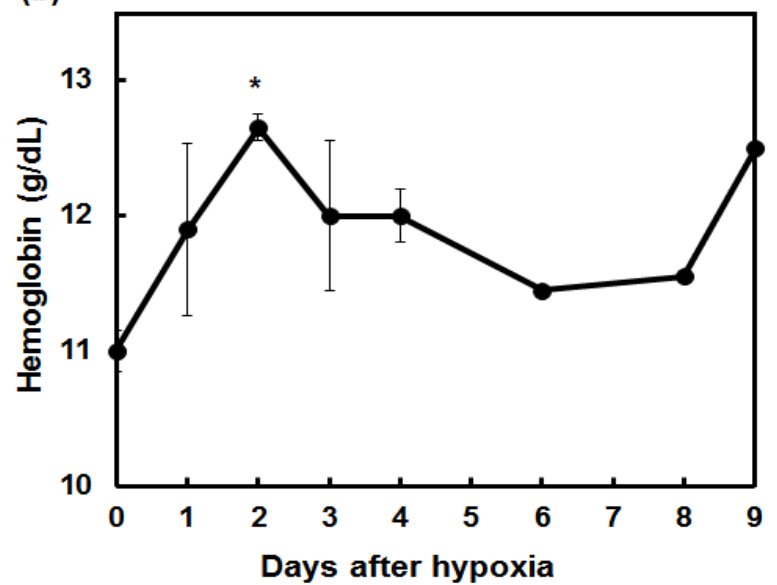

Figure 6: Mean $\pm \mathrm{SD}(\mathrm{N}=2)$ of reticulocyte (a) and hemoglobin (b) levels measured after response to $10 \%$ hypoxic exposure for 6 hours. *Values significantly different compared with the control group $\left({ }^{*} P<0.05\right.$, ${ }^{* *} P<0.01$, $\left.{ }^{* * *} P<0.001\right)$. 


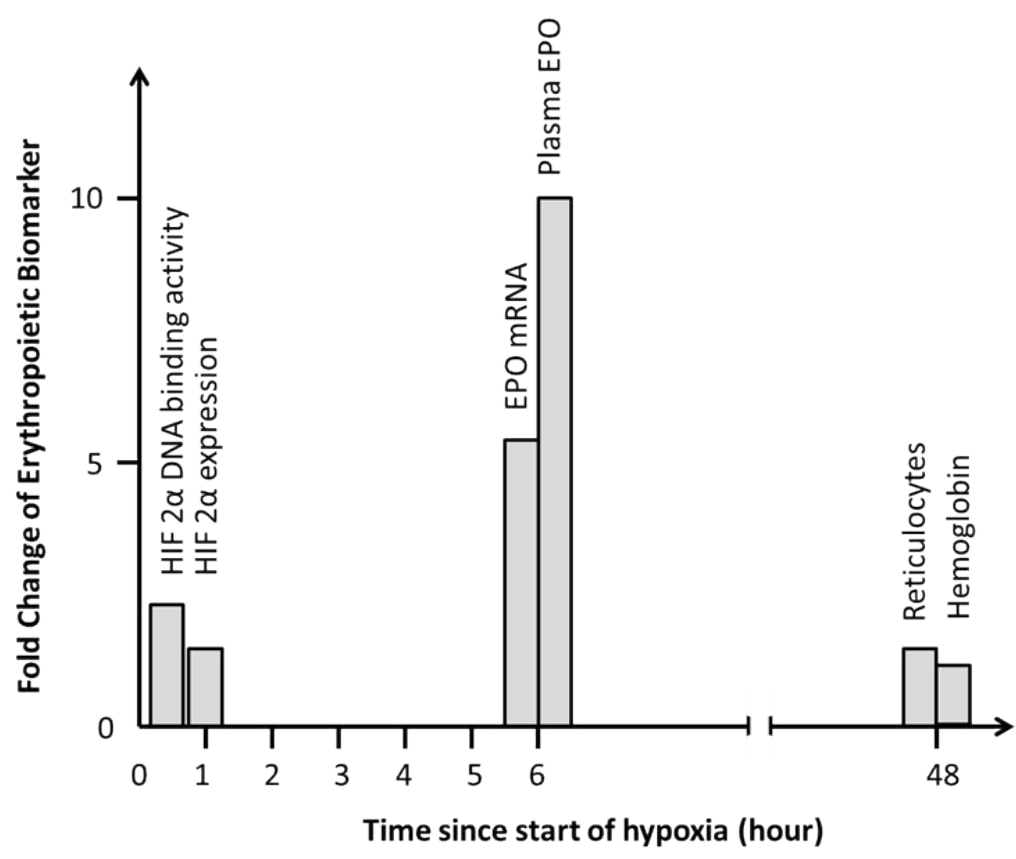

Figure 7: Demonstration of the time line of the maximum fold change of each erythropoietic biomarker.

\begin{tabular}{|c|c|c|c|c|}
\hline Biomarker & $\begin{array}{c}\text { Baseline } \\
\text { (mean } \pm \text { SD) }\end{array}$ & $\begin{array}{c}\text { Peak time } \\
\text { (unit) }\end{array}$ & $\begin{array}{c}\text { Peak value } \\
\text { (mean } \pm \text { SE) }\end{array}$ & P value \\
\hline HIF-2 $\alpha$ expression & $1 \pm 0.62$ (normalized) & $1(\mathrm{~h})$ & $2.37 \pm 0.54$ & $<0.001$ \\
\hline $\begin{array}{c}\text { HIF-2 } \alpha \text { DNA binding } \\
\text { activity }\end{array}$ & $1 \pm 0.46$ (normalized) & $0.5(\mathrm{~h})$ & $1.45 \pm 0.37$ & $\sim 0.02$ \\
\hline EPO mRNA & $1 \pm 0.72$ (normalized) & $6(\mathrm{~h})$ & $6.02 \pm 0.82$ & $<0.001$ \\
\hline Plasma EPO & $254.9 \pm 305.4$ & $6(\mathrm{~h})$ & $2587.6 \pm 1127.6$ & $<0.001$ \\
\hline Reticulocytes & $21.6 \pm 2.6$ & 2 (day) & $31.9 \pm 6.5$ & $<0.05$ \\
\hline Hemoglobin & $11.0 \pm 0.9$ & 2 (day) & $12.7 \pm 0.7$ & $<0.05$ \\
\hline
\end{tabular}

Table 1: Peak times and peak values of erythropoietic biomarkers in response to $10 \%$ hypoxia of 6 hours. Statistical significant was determined using one-way ANOVA follow by Dunnett test.

assays in Hep3B cells, they provided genetic evidence that HIF-1 and HIF-2 have distinct roles in the regulation of hypoxia-inducible genes and that EPO is preferentially regulated by HIF-2 in the liverwhile HIF$1 \alpha$ bound to the unmodified EPO HRE fragment in vitro [4]. Paliege et al. concluded that in the adult kidney, HIF-2 $\alpha$ and erythropoietin mRNA colocalize only in cortical interstitial fibroblasts, which makes them the key cell type for renal erythropoietin synthesis as regulated by HIF-2 $\alpha$ [13]. HIF-2 $\alpha$ binding to the EPO HRE to regulatory sequences in certain genes depends on the availability and cooperation with other transcription factors that associate with the EPO gene [12,22,23]. However, the time course of each biomarker during or after hypoxia treatment is still unclear, especially for HIF-2 $\alpha$. In this study, we showed the time line of HIF- $2 \alpha$ protein expression and DNA binding activity during hypoxia in rats. We observed that the in vivo HIF-2a DNA binding activity increased in less than one hour and decreased afterwards below the baseline.

At the beginning of the hypoxia treatment, both of the HIF-2a protein expression and DNA binding activity increased in one hour and reached to the peak value, after which they decreased very fast below the baseline. Stiehl et al. also observed this phenomenon, for HIF-1 $\alpha$ expression in HEK293 cells cultured at 1\% oxygen for up to
72 hours, their results demonstrated that the HIF levels decline during long-term hypoxic period [24]. They showed that the prolonged hypoxia up-regulates PHD-2 and PHD-3 both in vitro cultured cell lines as well as in various tissue of mice exposed to hypoxic conditions, including kidneys. A hypothesis has been formulated that the upregulated PHD-2 and PHD-3 genes result in an increase of the level of cytoplasmic PHD-2 and PHD-3 which in turn down regulate HIF. Stiehl et al. suggested that the up-regulation of PHDs during hypoxia is an adaptation mechanism allowing a response to another hypoxic stress [24]. Similar behavior of HIF-2 $\alpha$ is also observed under in vitro conditions. Zhdanov et al. showed some results related to in vitro HIf$2 \alpha$ dynamics under severe hypoxic conditions of $3 \%$ and $0 \%$ for PC12 cells. They demonstrate that, for $\mathrm{N}$-cells exposed to $3 \% \mathrm{O}_{2}$, a transient increase in HIF- $2 \alpha$ was observed with maximum at 6-9 h. Over the next 15 h HIF-2 $\alpha$ gradually decreased, which is likely to be due to the activation of PHDs which down-regulate HIF- $\alpha$ by negative feedback mechanism $[25,26]$.

The transcription of EPO mRNA is regulated by the DNA binding activity of HIF-2 $\alpha$, which stimulates the production of EPO in plasma. We observed that the maximum value for both EPO mRNA levels and EPO plasma concentrations occurs at six-hour hypoxia treatment, compared with the HIF- $2 \alpha$ maximum of 1 hour. This suggests a delay between the transcription and synthesis of EPO. We observed EPO mRNA and plasma protein peaks at the end of hypoxia, it is likely that each of these biomarkers may continue to increase if the hypoxia treatment continues. Analysis of time courses implies that there exists a time delay of $\sim 4$ hours between EPO synthesis and initial HIF-2 $\alpha$ DNA binding.

The ability of EPO-producing cells to efficiently target HIF- $\alpha$ subunits for proteasomal degradation under normoxia is essential for normal erythropoiesis. Our data suggest that inhibition of HIF- $\alpha$ degradation in the kidney cortex substantially raises systemic EPO 
levels by 10 -fold which causes only a moderate increase of 1.5 fold in hemoglobin delayed by 2 days. Such a response in EPO concentrations are equivalent to the EPO IV dose of $400 \mathrm{mIU}$ assuming a specific activity of $160,000 \mathrm{IU} / \mathrm{mg}$, which is consistent with previous findings by Woo et al. for the lowest dose of 10 IU rhuEPO IV administration in Wistar rats $[27,28]$. Their data also shows an EPO peak of $\sim 300$ $\mathrm{mIU}(\sim 3000 \mathrm{pg} / \mathrm{mL})$ resulting in $\sim 1.5-2$ fold increase in reticulocytes within one day after EPO IV administration. Although the increase in reticulocyte counts in our experiment was marginal, we also observed a decline of reticulocyte counts below the baseline value after 6 days of post hypoxic period. This rebound effect was reported by Yan et al. [29]. They attributed this effect to the depletion of erythroid cell pools in the bone marrow due to EPO simulation. This observation is consistent with an early study on erythroid precursors in mice treated with rHuEPO [30].

Although kidney is the major site of EPO production under hypoxic conditions, in minor amounts, other organs such as the liver and the brain also produce EPO [5]. EPO is used in treatment of anemia resulting from chronic kidney disease and myelodysplasia, as a consequence of the treatment of cancer (chemotherapy and radiation), and from other critical illnesses (heart failure) [31]. EPO also acts as neuroprotective agent and plays an important role in the brain's response to neuronal injury [32]. Since EPO does not cross the intact blood-brain-barrier, most probably EPO is produced in the brain itself by astrocytes in an oxygen-dependent manner [33]. In view that neuronal cells carry the EPO receptor, Marti et al. proposed that EPO acts in a paracrine fashion in the central nervous system and might function as a protective factor against hypoxia-induced damage of neurons [33]. Further studies are necessary to confirm if the time course of erythropoietic marker in the brain resembles one in the kidney. This might imply a therapeutic use of mild intermittent hypoxia for neuroprotective purposes.

We established a relationship between hypoxia and specific tissue and circulating factors collected in rats. Since this aspect has not been investigated to date, our study provides new insights on erythropoiesis regulation by hypoxia with a particularly interesting role of HIF- $2 \alpha$. Our results for reticulocyte and hemoglobin responses lack statistical significance due to a small number of animals, but we still claim their validity. We have not included PHD as another marker in our studies. Future research should involve time courses of PHD to explain the HIF- $2 \alpha$ response. Also, an effort should be made to extend the duration of exposure beyond 6 hours to determine the peak time for the EPO response.

\section{Summary}

After 6 hours fewer than 10\% hypoxia, an increase in the levels of rat kidney cortex EPO mRNA, plasma EPO concentration and reticulocytes count is observed. The observed delays in peak response are consistent with times necessary for the stimulation for EPO mRNA transcription, synthesis of plasma EPO and enhanced release of reticulocytes. The tolerance effect observed in HIF- $2 \alpha$ time course implies existence of a counter-regulatory mechanism in a HIF- $2 \alpha$ mediated signal for mRNA production. The intermittent hypoxia can result in an increase of EPO levels in other organs activating this hormone function a cytoprotective factor.

\section{Acknowledgment}

This study was supported by funds from the National Institutes of Health Grant GM 57980.

\section{References}

1. Peacock AJ (1998) ABC of oxygen: oxygen at high altitude. BMJ 317: 10631066.

2. Ratcliffe PJ, O'Rourke JF, Maxwell PH, Pugh CW (1998) Oxygen sensing, hypoxia-inducible factor- 1 and the regulation of mammalian gene expression. J Exp Biol 201: 1153-1162.

3. Ebert BL, Bunn HF (1999) Regulation of the erythropoietin gene. Blood 94 1864-1877.

4. Rankin EB, Biju MP, Liu Q, Unger TL, Rha J, et al. (2007) Hypoxia-inducible factor-2 (HIF-2) regulates hepatic erythropoietin in vivo. J Clin Invest 117: 1068-1077.

5. Jelkmann W (2011) Regulation of erythropoietin production. J Physiol 589: 1251-1258.

6. Stockmann C, Fandrey J (2006) Hypoxia-induced erythropoietin production: a paradigm for oxygen-regulated gene expression. Clin Exp Pharmacol Physiol 33: 968-979.

7. Jaakkola P, Mole DR, Tian YM, Wilson MI, Gielbert J, et al. (2001) Targeting of HIF-alpha to the von Hippel-Lindau ubiquitylation complex by O2-regulated prolyl hydroxylation. Science 292: 468-472.

8. Epstein AC, Gleadle JM, McNeill LA, Hewitson KS, O'Rourke J, et al. (2001) C elegans EGL-9 and mammalian homologs define a family of dioxygenases that regulate HIF by prolyl hydroxylation. Cell 107: 43-54

9. Warnecke C, Zaborowska Z, Kurreck J, Erdmann VA, Frei U, et al. (2004) Differentiating the functional role of hypoxia-inducible factor (HIF)-1alpha and HIF-2alpha (EPAS-1) by the use of RNA interference: erythropoietin is a HIF 2alpha target gene in Hep3B and Kelly cells. FASEB J 18: 1462-1464.

10. Smith TG, Robbins PA, Ratcliffe PJ (2008) The human side of hypoxia-inducible factor. Br J Haematol 141: 325-334.

11. Wang GL, Semenza GL (1995) Purification and characterization of hypoxiainducible factor 1. J Biol Chem 270: 1230-1237.

12. Haase $\mathrm{VH}$ (2010) Hypoxic regulation of erythropoiesis and iron metabolism. Am J Physiol Renal Physiol 299: F1-13.

13. Paliege A, Rosenberger C, Bondke A, Sciesielski L, Shina A, et al. (2010) Hypoxia-inducible factor-2 alpha-expressing interstitial fibroblasts are the only renal cells that express erythropoietin under hypoxia-inducible factor stabilization. Kidney Int 77: 312-318.

14. Goldberg MA, Gaut CC, Bunn HF (1991) Erythropoietin mRNA levels are governed by both the rate of gene transcription and posttranscriptional events. Blood 77: 271-277.

15. Wiesener MS, Jürgensen JS, Rosenberger C, Scholze CK, Hörstrup JH, et al (2003) Widespread hypoxia-inducible expression of HIF-2alpha in distinct cell populations of different organs. FASEB J 17: 271-273.

16. Semenza GL (2000) HIF-1: mediator of physiological and pathophysiological responses to hypoxia. J Appl Physiol (1985) 88: 1474-1480.

17. Semenza GL, Jiang BH, Leung SW, Passantino R, Concordet JP, et al. (1996) Hypoxia response elements in the aldolase A, enolase 1, and lactate dehydrogenase A gene promoters contain essential binding sites for hypoxiainducible factor 1. J Biol Chem 271: 32529-32537.

18. Goidin D, Mamessier A, Staquet MJ, Schmitt D, Berthier-Vergnes O (2001) Ribosomal 18S RNA prevails over glyceraldehyde-3-phosphate dehydrogenase and beta-actin genes as internal standard for quantitative comparison of mRNA levels in invasive and noninvasive human melanoma cell subpopulations. Anal Biochem 295: 17-21.

19. Dean CB, Nielsen JD (2007) Generalized linear mixed models: a review and some extensions. Lifetime Data Anal 13: 497-512.

20. Wiczling P, Ait-Oudhia S, Krzyzanski W (2009) Flow cytometric analysis of reticulocyte maturation after erythropoietin administration in rats. Cytometry $A$ 75: $584-592$

21. Casarett LJ, Doull J, Klaassen CD (2001) Casarett and Doull's toxicology: the basic science of poisons (8th edn,). McGraw-Hill Medical Pub. Division. New York, USA, pp: 1236.

22. Semenza GL, Wang GL (1992) A nuclear factor induced by hypoxia via de novo protein synthesis binds to the human erythropoietin gene enhancer at a site required for transcriptional activation. Mol Cell Biol 12: 5447-5454.

23. Aprelikova O, Wood M, Tackett S, Chandramouli GV, Barrett JC (2006) Role of ETS transcription factors in the hypoxia-inducible factor-2 target gene 
Citation: Zhang Y, Singh I, Krzyzanski W (2014) Dynamics of Erythropoietic Markers in Response to Hypoxia in Rats. J Blood Disorders Transf 5: 197. doi: 10.4172/2155-9864.1000197

Page 8 of 8

selection. Cancer Res 66: 5641-5647.

24. Stiehl DP, Wirthner R, Köditz J, Spielmann P, Camenisch G, et al. (2006) Increased prolyl 4-hydroxylase domain proteins compensate for decreased oxygen levels. Evidence for an autoregulatory oxygen-sensing system. J Bio Chem 281: 23482-23491.

25. D’Angelo G, Duplan E, Boyer N, Vigne P, Frelin C (2003) Hypoxia up-regulates prolyl hydroxylase activity: a feedback mechanism that limits HIF-1 responses during reoxygenation. J Biol Chem 278: 38183-38187.

26. Zhdanov AV, Dmitriev RI, Golubeva AV, Gavrilova SA, Papkovsky DB (2013) Chronic hypoxia leads to a glycolytic phenotype and suppressed HIF-2 signaling in PC12 cells. Biochim Biophys Acta 1830: 3553-3569.

27. Fisher JW, Nakashima J (1992) The role of hypoxia in renal production of erythropoietin. Cancer 70: 928-939.

28. Woo S, Krzyzanski W, Jusko WJ (2007) Target-mediated pharmacokinetic and pharmacodynamic model of recombinant human erythropoietin (rHuEPO). J Pharmacokinet Pharmacodyn 34: 849-868.
29. Yan X, Ait-Oudhia S, Krzyzanski W (2013) Erythropoietin-induced erythroid precursor pool depletion causes erythropoietin hyporesponsiveness. Pharm Res 30: 1026-1036.

30. Bugelski PJ, Nesspor T, Volk A, O'Brien J, Makropoulos D, et al. (2008) Pharmacodynamics of recombinant human erythropoietin in murine bone marrow. Pharm Res 25: 369-378.

31. Coleman T, Brines M (2004) Science review: recombinant human erythropoietin in critical illness: a role beyond anemia? Crit Care 8: 337-341.

32. Siren AL, Fratelli M, Brines M, Goemans C, Casagrande S, et al. (2001) Erythropoietin prevents neuronal apoptosis after cerebral ischemia and metabolic stress. Proc Natl Acad Sci USA 98: 4044-4049.

33. Marti HH, Gassmann M, Wenger RH, Kvietikova I, Morganti-Kossmann MC, et al. (1997) Detection of erythropoietin in human liquor: intrinsic erythropoietin production in the brain. Kidney Int 51: 416-418. 